\title{
BMJ Open Does digital health technology improve physicians' job satisfaction and work- life balance? A cross-sectional national survey and regression analysis using an instrumental variable
}

To cite: Zaresani A, Scott A. Does digital health technology improve physicians' job satisfaction and work-life balance? A cross-sectional national survey and regression analysis using an instrumental variable. BMJ Open 2020;10:e041690. doi:10.1136/ bmjopen-2020-041690

- Prepublication history and supplemental material for this paper is available online. To view these files, please visit the journal online (http://dx.doi. org/10.1136/bmjopen-2020041690).

Received 15 June 2020 Revised 21 0ctober 2020 Accepted 19 November 2020

Check for updates

(c) Author(s) (or their employer(s)) 2021. Re-use permitted under CC BY-NC. No commercial re-use. See rights and permissions. Published by BMJ.

${ }^{1}$ University of Manitoba, Institute for Labor Economics (IZA) and Tax and Transfer Policy Institute (TTPI) at The Australian National University, Winnipeg, Manitoba, Canada

${ }^{2}$ Melbourne Institute of Applied Economic and Social Research, University of Melbourne, Carlton, Victoria, Australia

Correspondence to

Dr Arezou Zaresani;

Arezou.Zaresani@umanitoba.ca

\section{ABSTRACT}

Objectives To examine the association between physicians' use of digital health technology and their job satisfaction and work-life balance.

Design A cross-sectional nationally representative survey of physicians and probit regression models were used to examine the association between using digital health technology and the probability of reporting high job satisfaction and a good work-life balance. Models included a rich set of covariates, including physicians' personality traits, and instrumental variable analysis was used to control for bias from unobservable confounders and reverse causality.

Setting Clinical practice settings in Australia, including physicians working in primary care, hospitals, outpatient settings, and physicians working in the public and private sectors.

Participants Respondents to wave 11 (2018-2019) of the Medicine in Australia: Balancing Employment and Life (MABEL) longitudinal survey of doctors. The analysis sample included a broadly nationally representative sample of 7043 physicians, including general practitioners, specialists and physicians in training.

Primary and secondary outcome measures The proportion of respondents who used any digital health technology; proportion answered 'moderately satisfied' or 'very satisfied' to the statement on job satisfaction: 'Taking everything into account, how do you feel about your work'; proportion agreeing or strongly agreeing to the statement on work-life balance: 'The balance between my personal and professional commitments is about right.'

Results Physicians with positive beliefs about the effectiveness of using digital health technology were 3.8 percentage points ( $95 \% \mathrm{Cl} 2.7$ to 5.0 ) more likely to use digital health technology compared with those who did not. Physicians with colleagues who already used digital health technology were also 4.1 percentage points $(95 \% \mathrm{Cl}$ 2.6 to 5.6) more likely to use digital health technology. The availability of IT support and lack of privacy concerns increased the probability of using digital health technology by 1.6 percentage points $(95 \% \mathrm{Cl} 1.0$ to 2.3$)$ and 0.5 percentage points $(95 \% \mathrm{Cl} 0.1$ to 1.0$)$. Physicians who used digital health technology were 14.2 percentage points $(95 \% \mathrm{Cl}-1.3$ to 29.7$)$ and 20.3 percentage points $(95 \% \mathrm{Cl}$ 2.4 to 38.1 ) more likely to report respectively higher job

\section{Strengths and limitations of this study}

- It provided new evidence on how physicians' use of digital health technology improves their job satisfaction and work-life balance.

- It used a unique and rich data from the Medicine in Australia: Balancing Employment and Life (MABEL) survey, including physicians' personality traits.

- Instrumental variables were used to account for reverse causality issues and unobserved confounding factors.

- The data were a cross-sectional survey, and there could be other unobserved factors that were not controlled for, requiring a cautious interpretation of the findings.

satisfaction and good work-life balance, compared with the physicians who did not use it.

Conclusions Findings suggested digital health technology served more as a work resource than work demand for physicians who used it.

\section{INTRODUCTION}

Digital health technology, such as shared electronic health records, can improve information flow between healthcare providers and between providers and patients. Convincing busy physicians to use digital health technology (see box 1) in their practice requires evidence on the benefits to patients and evidence on the benefits and costs to the physicians themselves. There is a potential for digital health technology to save physicians' time by accessing patients' medical records, test results and medication information more quickly. Through sharing more standard information and making such information available at the point of care, digital health technology can reduce duplication of tests, reduce medication errors and improve patient safety. However, digital 


\section{Box 1 Activities physicians use digital health technology}

- Sending/receiving referrals from other health practitioners.

- Viewing pathology or diagnostic imaging results.

- Viewing pathology or diagnostic imaging results.

- Ordering pathology tests or diagnostic imaging.

- Storing advanced care planning documents

- Completing/viewing event summaries (eg, discharge summaries/ specialist reports).

Writing prescriptions.

- Viewing medicines information.

Viewing immunisation information.

- Viewing patient information entered by other health professionals outside my main place of work.

- Entering/updating patient information during or after consultations or procedures.

- Clinical audit and research.

- Using digital decision support tools to help inform clinical decisions (eg, clinical dashboards; automated alerts, warnings and reminders; algorithms; electronic clinical guidelines and pathways).

health technology can also be an additional work demand as extra time is needed to input patients' health information into the electronic record and read and interpret the other healthcare providers' information. The net impact of these factors influences physicians' decision to use digital health technology.

Physicians' use of digital health technology is determined by a range of factors that have been summarised in previous literature reviews and qualitative research. ${ }^{1-3}$ Previous systematic reviews on the impact of using digital health technology on time use, ${ }^{4}$ health outcomes, patient satisfaction and processes of patient care ${ }^{5-7}$ are not conclusive. A systematic review examining the effects on quality of care showed positive effects on documentation time, guideline adherence, medication errors and adverse drug events. ${ }^{8}$ Findings on the effects of using digital health technology in hospital settings also are not conclusive. ${ }^{9}$ In ambulatory and primary care, a recent survey showed an association between the use of electronic medical records and physicians' burnout and stress, but that other working conditions mattered more. ${ }^{10}$ Previous research in Australia found that general practitioners who agreed that IT was useful were more likely to experience higher work-life balance. ${ }^{11}$

This paper aims to examine the factors associated with the use of digital health technology by physicians and then examine the association between the use of digital health technology and physicians' job satisfaction and work-life balance.

\section{Australian healthcare system}

Medicare is Australia's universal healthcare system funded through taxation. Medicare funds all medical services provided by private medical practitioners (general practitioners and other specialists) outside of hospitals by providing subsidies to patients for each service, including consultations and procedures. Patients are charged using a fee-for-service scheme. Medicare also provides around half of the funding to public hospitals, with the rest provided by States and Territories who own and manage public hospitals. The Federal Government also provides subsidies for private health insurance, with $43 \%$ of the population holding private health insurance, and around half of all hospitals are privately owned.

My Health Record, the Australian national electronic shared health record, was introduced in 2019 where all Australians have a record unless they opt out. ${ }^{12}$ The use of My Health Record by patients and healthcare providers is voluntary. They also continue to use their own systems, such that there remains variation in general use by physicians and how digital health technology are used.

Historically, general practitioners, who are organised in small group practices with around 5\% working in solo practices, have been responsible for procuring their own IT systems supported by government funding delivered through the Practice Incentive Program since 1998. The majority of general practitioners' practices are computerised, but with variation in use, including storage of electronic health records. Other specialists can work in public and/or private hospitals and also in their own private offices. Public hospitals are run by each State and Territory Government and have some autonomy, which varies across States and Territories, to procure their own IT systems, again with government funding, but leading to considerable variation in the systems used and how they are used with little interoperability between hospitals and between hospitals and primary care.

\section{METHODS}

Patient and public involvement statement

There was no patient or public involvement in this study.

\section{Source of data}

The Medicine in Australia: Balancing Employment and Life (MABEL) survey is an annual longitudinal survey of physicians in clinical practice focusing on workforce participation, labour supply and its determinants. The survey is representative of the physicians' population in Australia and provides information on physicians' characteristics, family circumstances, geographical location, qualifications and practice settings. The first wave of MABEL was conducted in 2008, where the population of 54750 physicians in clinical practice in Australia were invited to participate in the survey. The 10498 doctors who participated in the baseline cohort were representative of the physicians' population in Australia in 2008 with respect to age, gender and geographical location. ${ }^{13}{ }^{14} \mathrm{In}$ each subsequent wave, a new cohort of physicians were invited to participate in the survey in addition to all those who participated in the survey in the previous waves. A paper copy of the survey questionnaire and online login information was mailed to the physicians' work address, followed by three reminders for each wave. Physicians in 
rural areas received an $\$ A 100$ cheque along with the invitation to participate in the survey. ${ }^{15}$

\section{Study population}

The 11th wave of the MABEL questionnaire was sent to 27829 physicians in August 2018. This included 17103 physicians who had previously responded to the earlier waves, 4525 who were new to the sample frame and 4698 from a $10 \%$ boost sample of physicians who previously never responded. ${ }^{15}$

\section{Digital health technology}

The 11th wave of the survey included new questions on the use of digital health technology. ${ }^{16}$ These questions were developed based on previous systematic literature reviews, ${ }^{23}$ selective interviews with a small number of physicians, and previous research conducted by the Australian Department of Health and the Australian Digital Health Agency. ${ }^{17-19}$ The questions were pre-tested in a pilot survey with several changes made to the main survey questions. The questions were designed to be the same across the many contexts, work settings and specialties in which physicians work. The questions on use were focused on whether or not respondents had used digital health technology for a pre-specified range of activities. In the analysis, the use of digital health technology was measured as a binary variable equal to one for physicians who reported using it for at least one of the activities in box 1 .

The survey also asked physicians about their attitudes and beliefs around digital health technology. The questions covered four main areas of attitudes and beliefs that were hypothesised to influence the use: peer effects, effectiveness of digital health technology, data sharing and privacy concerns, and availability of IT support. The most generally posed questions were used to construct binary variables which were defined equal to one if respondents 'agreed' or 'strongly agreed' with the statements: 'Digital health technology improve care processes (eg, improve care coordination, continuity of care, reduce duplication),' and 'Colleagues and support staff already extensively use digital health technology,' and 'I receive support and advice on IT security from my main place of work (eg, on password protection/encryption, staff training, firewalls, back-ups),' and 'I have no concerns about data privacy or security.'

\section{Job satisfaction and work-life balance}

Job satisfaction was measured using the 10-item short version of the Warr-Cook-Wall Job Satisfaction Scale. ${ }^{20} 21$ This was validated in the MABEL cohort of Australian clinical medical practitioners. ${ }^{22}$ Overall job satisfaction was coded as a binary variable equal to one for respondents who answered 'moderately satisfied' or 'very satisfied' to the question asking: 'Taking everything into account, how do you feel about your work.' Work-life balance was defined as a binary variable equal to one for respondents who answered 'agree' or 'strongly agree' to the question asking: 'The balance between my personal and professional commitments is about right.'

\section{Other variables}

The analyses included several control variables that have been shown to influence job satisfaction and work-life balance: gender, age, marital status (single as the base, living in with a partner), spouse employment status (unemployed or not applicable as the base, full time or part-time), having at least one child below 5 years old, geographical location including whether in a metropolitan area, state, and socioeconomic status of the postcode measured by the Socio-Economic Indexes For Areas of Relative Socio-economic Advantage and Disadvantage (SEIFA-IRSAD). ${ }^{23}$ This index is constructed by the Australian Bureau of Statistics based on information from the 5 yearly Census, where higher scores indicate greater advantage.

Other variables included whether the physician worked in the public, private, or both public and private sectors, whether they were an overseas trained physician, whether they graduated from one of the top-eight Australian medical schools and whether they held a fellowship of their college. Physicians' personality traits were measured using the 15 -item factor model. ${ }^{24}$ The big-five personality traits included in the models were extraversion, agreeableness, conscientiousness, neuroticism and openness, and were standardised to have a mean of zero and SD of one.Statistical analysis

\section{STATISTICAL ANALYSIS}

Descriptive statistics of all variables were presented. Differences between physicians who used digital health technology and those who did not were tested using two-sided t-tests for the means and proportions. Multivariate probit regression models were used, given the binary nature of the outcome variables, the use of instrumental variables estimation and the ease of interpreting results as changes in proportions. The first model included the use of digital health technology as the dependent variable to examine the association between using digital health technology with peer effects, physicians' beliefs about the effectiveness of digital health technology, data sharing and privacy concerns, availability of IT support and physicians' characteristics, including their personality traits.

The second and third probit models used job satisfaction and work-life balance as outcome variables to examine the association with the use of digital health technology. Although a rich set of control variables were included, there may be unobserved confounding factors correlated with the decision to use digital health technology.

Further, these models might suffer from reverse causality (simultaneity) where physicians with higher job satisfaction or good work-life balance might also be more likely to use digital health technology, resulting in an overestimation of the size of the association from the probit models. To adjust for these potential biases, probit 
models with an instrumental variable were estimated using a maximum-likelihood method. ${ }^{25}$

An instrumental variable is an observable factor related to physicians' choice of using digital health technology, but unrelated to their work satisfaction or work-life balance. We used physicians' beliefs about digital health technology's effectiveness for improving the care process as an instrumental variable for using digital health technology since it had the strongest association with the use of digital health technology from our first model. The Wald statistics were constructed to test the exogeneity of the instrumental variable, whether it was correlated with the error term of the job satisfaction and work-life balance probit models, which is a required condition for the validity of the analysis. ${ }^{26}$

Probability weights were used to adjust the descriptive statistics and the regression models to represent the population regarding age, gender, physician type and location. ${ }^{15}$ All the estimates from probit models were presented in terms of the average marginal effect, which indicates the change in the probability of the outcome variable due to a one-unit change in the corresponding independent variable. The SEs were clustered at the postcode level to account for the correlations between respondents in the same geographical area due to similar internet speeds and similarity of the population and physicians within the same geographical area.

\section{Results}

Of the 27929 physicians whom to the survey was sent, 9361 responded $(33.5 \%)$. These were slightly underrepresented in the age groups 40-59years old and over-represented by women ( $48.3 \%$ vs $40.9 \%$ in the population). Moreover, $35.1 \%$ were general practitioners, compared with $41.1 \%$ in the population; $41 \%$ were specialists compared with $38.9 \%$ in the population; $17.5 \%$ were a pre-vocational physician in training compared with $14 \%$ in the population; and $6.4 \%$ were doctors in vocational (specialty) training programmes compared with $6 \%$ in the population. Respondents were more closely representative of location in terms of state, and there was a higher proportion from non-metropolitan areas (24\% vs $29.9 \%$ from metropolitan areas). ${ }^{15}$

Our study sample included 7043 physicians working in clinical practice who answered the digital health technology questions and all the other questions used in the analysis. In total, 6537 physicians $(92.82 \%)$ used digital health technology, where $35.4 \%$ were general practitioners (19.6\% used digital health technology) and $41.2 \%$ were specialists (61.9\% users). The remaining $23.4 \%$ were physicians in training ( $18.7 \%$ users).

Figure 1 shows the activities which physicians use digital health technology for, broken down by physicians' type. There is quite lots of variation in how physicians use digital health technology; almost all physicians use digital health technology for viewing pathology and imaging

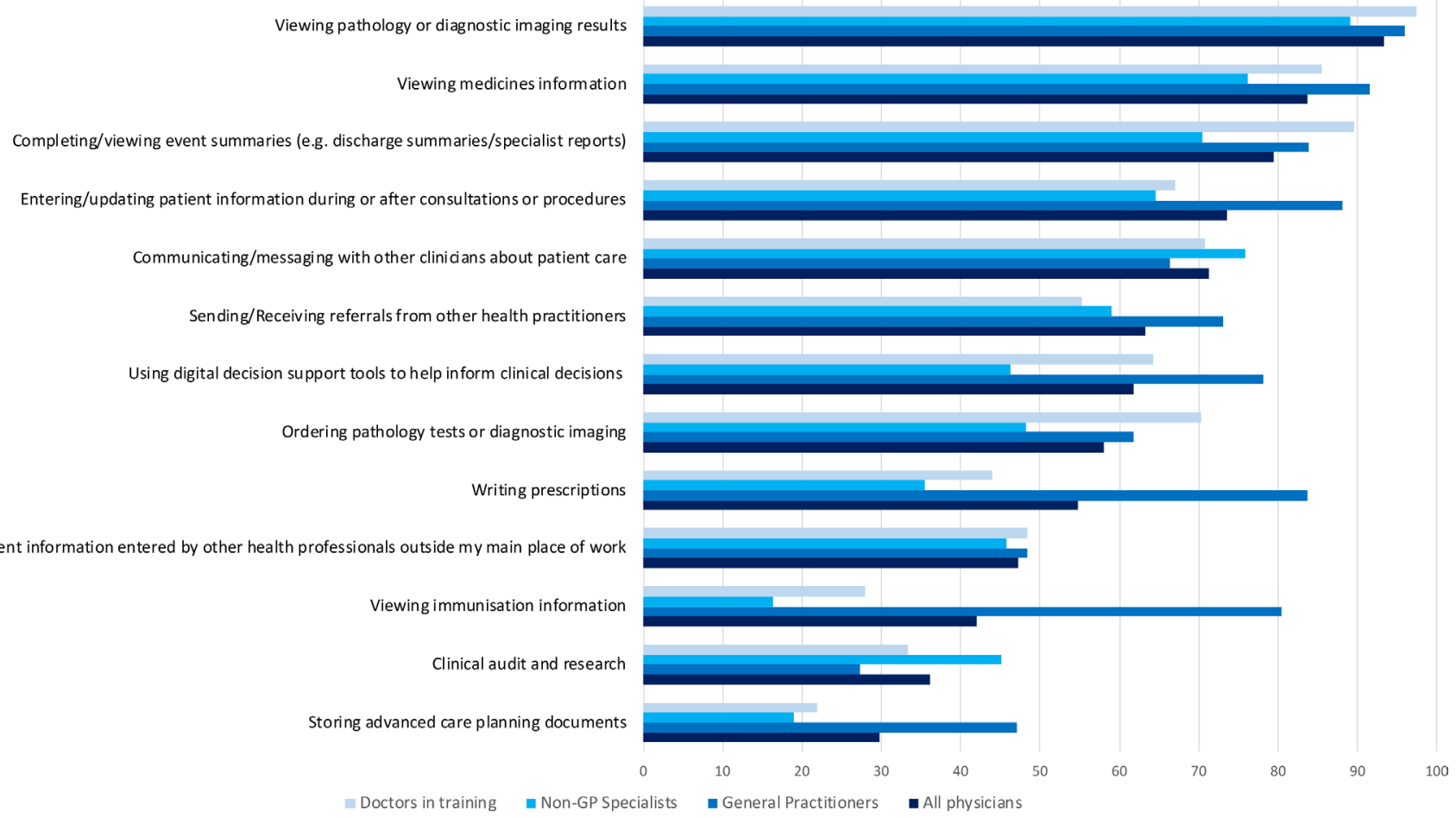

Figure 1 Use of digital health technology among Australian physicians. This figure shows the activities for which Australian physicians use digital health technology, broken down by the physicians' type. The figure uses a question in the 11th wave of The Medicine in Australia: Balancing Employment and Life (MABEL) survey data, asking physicians, 'In your last usual week at work, did you use digital health technologies/solutions for the following activities?' The figure presents the percentage of physicians who answered 'Yes'. 
results while less than half of them use digital health technology for sorting advanced care planning documents.

Table 1 compares the characteristics of physicians who used digital health technology with those who did not. Physicians who used digital health technology were older, more likely to be male, more likely to have a live-in partner, who was also more likely to be employed (either part-time or full-time). Users were more likely to hold fellowship of their college, and more likely to work either solely in public or private practice than doctors working across both settings. There were no differences in the personality traits between physicians who used and did not use digital health technology. Most of the physicians who used digital health technology had positive beliefs about digital health technology's effectiveness in improving the care process, had colleagues who also used it, had IT support in their practice and had no privacy concerns. The users also were more likely to be satisfied with their job and have a good work-life balance.

The estimates of average marginal effects from the factors associated with the probability of using digital health technology are shown in table 2, with full results provided in online supplemental table 1 . After adjusting for the variables presented in table 1, positive beliefs about the effectiveness of digital health technology for improving the care process and having colleagues who used digital health technology in their practice were associated with an increase in the probability of using digital health technology of 3.8 percentage points $(95 \% \mathrm{CI}$ 0.027 to 0.050$)$ and 4.1 percentage points $(95 \% \mathrm{CI}$ 0.026 to 0.056$)$, respectively. Availability of IT support (1.6 percentage points: $95 \%$ CI 0.010 to 0.023 ) and lack of privacy concerns ( 0.5 percentage points; $95 \%$ CI 0.001 to 0.010 ) were also associated with increased probability of use. Respondents aged between 40 and 59 were more likely to use digital health technology than those below 40 years old, but the effects were relatively small. Physicians with live-in partners who worked part-time (compared with not working) and physicians working in public or private practice only (compared with working in both sectors) were also more likely to use digital health technology. The probability of using digital health technology was lower for physicians with young children, those who graduated overseas, graduates from top Australian universities and physicians with the primary location of practice in the areas with lower socioeconomic status. The association between the use of digital health technology and physicians' big-five personality traits were relatively weak.

Estimates of the average marginal effects of using digital health technology on the probabilities of high job satisfaction and good work-life balance are shown in table 3, with full results provided in online supplemental tables 2 and 3. Using digital health technology increased the probability of higher job satisfaction and having a good work-life balance in both unadjusted and adjusted models. After adjusting for endogeneity/confounding using an instrumental variable, the estimates were slightly smaller but still relatively large. The estimate of the average marginal effect on the probability of having high job satisfaction fell from 16.2 percentage points (95\% CI 0.112 to 0.212 ) in the adjusted analysis to 14.2 percentage points $(95 \% \mathrm{CI}-0.013$ to 0.297$)$ in the instrumental variable analysis. The estimated effect on work-life balance fell from 23.2 percentage points (95\% CI 0.176 to 0.287 ) to 20.3 percentage points ( $95 \%$ CI 0.024 to 0.381 ) in the instrumental variable analysis. The CIs were wider in the instrumental variable analysis, suggesting a higher level of uncertainty around the size of the effect of digital health technology on the two outcomes.

The Wald statistics for testing exogeneity of the instrumental variable were 23.99 and 15.11 from the analysis for job satisfaction and work-life balance, respectively. The $\mathrm{p}$ values for both statistics were smaller than 0.001 , suggesting the instrumental variable's validity by rejecting the null hypothesis of a non-zero correlation between the instrumental variable and the error terms in the models.

\section{DISCUSSION}

In this nationally representative study of 7043 Australian physicians, positive beliefs about the effect of digital health technology on improving the care process and having colleagues who use digital health technology had the strongest association with the use of digital health technology, followed by having IT support, and lack of privacy concerns. There was a strong association between the use of digital health technology and high job satisfaction and good work-life balance. The largest effects were for general practitioners, followed by specialists and physicians in training. These positive associations persisted after controlling for physicians' practice and personal characteristics, including their personality traits, and using an instrumental variable to adjust for the bias dues to reverse causality and unobservable confounders.

Previous research on the effects of using digital health technology on various aspects of physicians' work is not conclusive. While some studies show that using digital health technology benefits some aspects of physicians' work, ${ }^{82728}$ other studies show that it does not or provide inconclusive results. ${ }^{4-79}$ This could be due to either the statistical method or the data used in these studies. Our study is the first to examine the association between using digital health technology with physicians' job satisfaction and building on a previous study examining the associations with the work-life balance. ${ }^{11}$ We used MABEL data, which is representative of the physician population in Australia. The data included a rich set of information on the physicians, including their personality traits. Further, we used an instrumental variable model to correct for the biases due to reverse causality and confounding factors. The results of this study suggested that digital health technology served more as a work resource for physicians rather than a work demand.

A limitation of this study was that the results were based on a cross-sectional survey. Although all the models were adjusted for a rich set of control variables, including 
Table 1 Descriptive characteristics of the physicians

\section{Characteristics (portion)}

Age (mean)

Male (=1)

Live in partner $(=1)$

Spouse labour force status

\begin{tabular}{llrr} 
Not in labour force/NA & 0.604 & 0.382 & $<0.001$ \\
\hline Part-time employment & 0.276 & 0.345 & 0.006 \\
\hline Full-time employment & 0.119 & 0.271 & $<0.001$ \\
\hline Young child (=1) & 0.155 & 0.097 & 0.002 \\
\hline Foreign graduate (=1) & 0.227 & 0.224 & 0.899 \\
\hline Top-eight Australian university graduate (=1) & 0.625 & 0.569 & 0.035 \\
\hline Fellowship of college (=1) & 0.712 & 0.697 & 0.511 \\
\hline Metropolitan area (=1) & 0.757 & 0.754 & 0.870 \\
Practice setting & & 0.406 & $<0.001$ \\
\hline Public only & 0.092 & 0.275 & $<0.001$ \\
\hline Private only & 0.196 & 0.317 & $<0.001$ \\
\hline Private and public & 0.710 & 1031.62 & 0.048 \\
Socio-Economic Indexes for Areas of Relative Socio-economic & 1039.935 & & 0.401
\end{tabular}

General practitioners

0.184

Specialists

0.645

0.170

Physicians in training

0.080

Colleagues and support staff already extensively use digital health technology

Believing in digital health technology improve care processes

(eg, improve care coordination, continuity of care and reduce duplication)

\begin{tabular}{llll} 
Has no concerns about data privacy or security & 0.034 & 0.144 & $<0.001$ \\
$\begin{array}{l}\text { Receiving support and advice on IT security from my main place } \\
\text { of work (eg, on password protection/encryption, staff training, } \\
\text { firewalls and back-ups) }\end{array}$ & 0.054 & 0.479 & $<0.001$ \\
$\begin{array}{l}\text { Personality trait: } \\
\text { Extraversion (standardised mean) }\end{array}$ & 0.005 & -0.100 & 0.776 \\
$\begin{array}{l}\text { Personality trait: } \\
\text { Agreeableness (standardised mean) }\end{array}$ & -0.070 & -0.049 & 0.717 \\
$\begin{array}{l}\text { Personality trait: } \\
\text { Consciousness (standardised mean) }\end{array}$ & -0.009 & 0.022 & 0.569 \\
$\begin{array}{l}\text { Personality trait: } \\
\text { Neuroticism (standardised mean) }\end{array}$ & -0.121 & 0.003 & 0.012 \\
$\begin{array}{l}\text { Personality trait: } \\
\text { Openness (standardised mean) }\end{array}$ & 0.069 & 0.007 & 0.240 \\
\hline $\begin{array}{l}\text { Job satisfaction (moderately/very satisfied=1) } \\
\text { Work-life balance (agree/strongly agree=1) }\end{array}$ & 0.250 & 0.397 & $<0.001$ \\
\hline
\end{tabular}

This table presents the descriptive characteristics of the 7043 physicians who answered all the questions on the use of digital health technology and other variables used in the regression analysis. The reported proportions and the means are adjusted for the cross-section weights. The reported $p$ values are from two-sided t-stats testing the null hypothesis that the means and proportions are the same for those who use and those who do not use digital health technology.

NA, not applicable.

$\begin{array}{rrr}43.956 & 47.075 & 0.044 \\ 0.508 & 0.558 & 0.074 \\ 0.551 & 0.797 & <0.001\end{array}$

0.069

0.641

$<0.001$

0.215

0.403

$<0.001$

\section{Do not use digital health Use digital health $\mathbf{P}$ technology ( $\mathrm{N}=6537)$ value}


Table 2 Factors affecting the use of digital health technology

\section{Factors affecting the use of digital health technology (agree/strongly agree with statements below)}

Colleagues and support staff already extensively use digital health technology

Digital health technology improves care processes (eg, improve care coordination, continuity of care and reduce duplication)

$\begin{array}{ll}\text { I have no concerns about data privacy or security } & 0.005 \text { (0.001 to } 0.010) \\ \text { I receive support and advice on IT security from my main place of work (eg, on } & 0.016 \text { (0.010 to 0.023) } \\ \text { password protection/encryption, staff training, firewalls and back-ups) } & \end{array}$

Average marginal effects on the probability of using digital health technology $(95 \% \mathrm{Cl})$

0.041 ( 0.026 to 0.056$)$

0.038 (0.027 to 0.050$)$

0.005 (0.001 to 0.010$)$

password protection/encryption, staff training, firewalls and back-ups)

This table presents the estimated change in the probability of using digital health technology from a probit regression model. The estimates are adjusted for physicians' characteristics shown in table 1, with full results presented in online supplemental table 1. The study sample includes 7043 physicians who answered questions on the use of digital health technology, and all the variables used in the analysis. The estimates are adjusted for the cross-sectional survey weights. The $95 \%$ Cls presented in parentheses are based on SEs clustered at the postcode level.
Table 3 Estimated average marginal effect on the probability of high job satisfaction and good work-life balance from using digital health technology

\begin{tabular}{ll}
\hline Model & $\begin{array}{l}\text { Estimated average } \\
\text { marginal effect on the } \\
\text { probability }(95 \% \mathrm{Cl})\end{array}$ \\
\hline $\begin{array}{l}\text { Job satisfaction } \\
\text { Unadjusted analysis }\end{array}$ & $0.174(0.102$ to 0.246$)$ \\
\hline Adjusted analysis & $0.162(0.112$ to 0.212$)$ \\
\hline General practitioners only & $0.246(0.180$ to 0.313$)$ \\
Specialists only & $0.107(0.021$ to 0.193$)$ \\
\hline Physician in training only & $0.080(-0.038$ to 0.198$)$ \\
\hline Adjusted IV analysis & $0.142(-0.013$ to 0.297$)$ \\
\hline Work-life balance & $0.283(0.198$ to 0.367$)$ \\
\hline Unadjusted analysis & $0.232(0.176$ to 0.287$)$ \\
Adjusted analysis & $0.213(0.125$ to 0.301$)$ \\
\hline General practitioner only & $0.176(0.086$ to 0.2767$)$ \\
\hline Specialist only & $0.194(0.075$ to 0.312$)$ \\
\hline Physician in training only & $0.203(0.024$ to 0.381) \\
\hline Adjusted IV analysis &
\end{tabular}

This table presents the estimated average marginal change in the probability of high job satisfaction and good work-life balance from using digital health technology. Each estimate is from a separate probit regression model that includes a full set of covariates from table 1. All the adjusted estimates include the state the practice is located and the physicians' personality traits. The estimates for the specialists are adjusted for their specialties. The study sample includes 7043 physicians who answered questions on the use of digital health technology, and all the variables used in the analysis. All the estimates are also adjusted for the cross-sectional survey weights. The $95 \%$ Cls presented in parentheses are based on SEs clustered at the postcode level. Detailed estimates are shown in online supplemental tables 2 and 3.

$P$ value of Wald test of exogeneity $<0.001$.

IV, instrumental variable. physicians' personality traits, and an instrumental variable was used to adjust for the bias, there still could be other unobserved factors that were not controlled for, requiring a cautious interpretation of the findings.

Another limitation of this study was that this research did not directly examine the acquisition and procurement of IT systems by healthcare providers, in which a range of factors will play a role that were not included in the analysis, including the mix of public and private funding for different types of healthcare providers. General practitioners receive subsidies from governments, while public hospitals conduct their own procurement with government oversight and funding, and private hospitals operate in the private market. A better understating of these factors would help the more efficient design of policies to increase the use of digital health technology and improve the flow of the healthcare system. This is also related to the separation of the effects from the organisational level, where organisational decisions determine the use rather than individual preferences. The results show that those in only public or only private settings were more likely to use digital health technology than those who worked across both sectors.

This study provided new relevant evidence on the association between the use of digital health technology and physicians' job satisfaction and work-life balance. Educational programmes for physicians to encourage the use should focus on persuading them of the benefits of using digital health technology, colleagues' use and ensuring sufficient IT support.

Contributors AZ conducted the literature search, statistical analysis and contributed to data interpretation and drafting of the manuscript. AS provided management oversight of the project and contributed to data interpretation and drafting of the manuscript

Funding This research was funded by the Australian Digital Health Agency. We used data from the Medicine in Australia: Balancing Employment and Life (MABEL) longitudinal survey. Funding for MABEL was provided by the National Health and Medical Research Council (2007-2016: 454799 and 1019605); the 
Australian Government Department of Health and Ageing (2008); Health Workforce Australia (2013); and in 2017, The University of Melbourne, Medibank Better Health Foundation, New South Wales Department of Health, and Victorian Department of Health and Human Services. In 2018, MABEL was funded by the Australian Government Department of Health, Victorian Department of Health and Human Services, and the Australian Digital Health Agency. The study was approved by The University of Melbourne Faculty of Business and Economics Human Ethics Advisory Group (Ref: 0709559) and the Monash University Standing Committee on Ethics in Research Involving Humans (Ref: CF07/1102-2007000291).

Competing interests None declared.

Patient consent for publication Not required.

Provenance and peer review Not commissioned; externally peer reviewed.

Data availability statement Data may be obtained from a third party and are not publicly available (for more information on how to access MABEL data, see https:// melbourneinstitute.unimelb.edu.au/mabel/for-researchers/data).

Supplemental material This content has been supplied by the author(s). It has not been vetted by BMJ Publishing Group Limited (BMJ) and may not have been peer-reviewed. Any opinions or recommendations discussed are solely those of the author(s) and are not endorsed by BMJ. BMJ disclaims all liability and responsibility arising from any reliance placed on the content. Where the content includes any translated material, BMJ does not warrant the accuracy and reliability of the translations (including but not limited to local regulations, clinical guidelines, terminology, drug names and drug dosages), and is not responsible for any error and/or omissions arising from translation and adaptation or otherwise.

Open access This is an open access article distributed in accordance with the Creative Commons Attribution Non Commercial (CC BY-NC 4.0) license, which permits others to distribute, remix, adapt, build upon this work non-commercially, and license their derivative works on different terms, provided the original work is properly cited, appropriate credit is given, any changes made indicated, and the use is non-commercial. See: http://creativecommons.org/licenses/by-nc/4.0/.

ORCID iD

Arezou Zaresani http://orcid.org/0000-0002-6271-9374

\section{REFERENCES}

1 Barr NG, Randall GE, Archer NP, et al. Physician communication via Internet-enabled technology: a systematic review. Health Informatics J 2019;25:919-34.

2 Gesulga JM, Berjame A, Moquiala KS, et al. Barriers to electronic health record system implementation and information systems resources: a structured review. Procedia Comput Sci 2017;124:544-51.

3 Castillo VH, Martínez-García Al, Pulido JRG. A knowledge-based taxonomy of critical factors for adopting electronic health record systems by physicians: a systematic literature review. BMC Med Inform Decis Mak 2010;10:60.

4 Poissant L, Pereira J, Tamblyn R. The impact of electronic health records on time efficiency of physicians and nurses: a systematic review. J Am Med Inform Assoc 2005;12:505-16.

5 Moja L, Kwag KH, Lytras T, et al. Effectiveness of computerized decision support systems linked to electronic health records: a systematic review and meta-analysis. Am J Public Health 2014; $104: 22$

6 Ammenwerth E, Schnell-Inderst P, Hoerbst A. The impact of electronic patient portals on patient care: a systematic review of controlled trials. J Med Internet Res 2012;14:e162.
7 Irani JS, Middleton JL, Marfatia R, et al. The use of electronic health records in the exam room and patient satisfaction: a systematic review. J Am Board Fam Med 2009;22:553-62.

8 Campanella $\mathrm{P}$, Lovato $\mathrm{E}$, Marone $\mathrm{C}$, et al. The impact of electronic health records on healthcare quality: a systematic review and metaanalysis. Eur J Public Health 2016;26:60-4.

9 Eden R, Burton-Jones A, Staib A, et al. The impacts of eHealth upon hospital practice: synthesis of the current literature. Deeble Inst Evid Br 2017;16:6.

10 Kroth PJ, Morioka-Douglas N, Veres S, et al. Association of electronic health record design and use factors with clinician stress and burnout. JAMA Network Open 2019;2:e199609.

11 Bardoel EA, Drago R. Does the quality of information technology support affect work-life balance? A study of Australian physicians. Int J Hum Resour Manag 2016;27:2604-20.

12 Hambleton SJ, Aloizos AM J. Australia's digital health journey. Med $J$ Aust 2019;210:S5-6.

13 Joyce CM, Scott A, Jeon S-H, et al. The "medicine in Australia: balancing employment and Life (MABEL)" longitudinal survey - protocol and baseline data for a prospective cohort study of Australian doctors' workforce participation. BMC Health Serv Res 2010;10:1-10.

14 Taylor T, La N, Scott A, et al. Mabel user manual: wave 8 release. Melb Inst Appl Econ Soc Res Univ Melb 2016.

15 Szawlowski S, Harrap B, Leahy A, et al. Medicine in Australia: balancing employment and life (MABEL) user manual: wave 11 release. Melb Inst Appl Econ Soc Res Univ Melbourne, Melb 2020.

16 Medicine in Australia: balancing employment and life (MABEL): questionnaires for wave 11. Melb Inst Appl Econ Soc Res Univ Melbourne, Melb 2018.

17 Siggins M. Evaluation of the participation trials for the my health record 2016.

18 Department of Health and Ageing. The readiness of Australian general practitioners for the eHealth record 2011.

19 Department of Health and Ageing, Australian Government. The eHealth readiness of Australia's medical specialists 2011.

20 Ham V I, Verhoeven AH, Groenier KH, et al. Job satisfaction among general practitioners: a systematic literature review. Eur J Gen Pract 2006;12:174-80.

21 Warr P, Cook J, Wall T. Scales for the measurement of some work attitudes and aspects of psychological well-being. J Occup Organ Psychol 1979;52:129-48.

22 Hills D, Joyce C, Humphreys J. Validation of a job satisfaction scale in the Australian clinical medical workforce. Eval Health Prof 2012;35:47-76.

23 Australian Bureau of Statistics. Socio-economic indexes for areas, 2020. Available: https://www.abs.gov.au/websitedbs/censushome. nsf/home/seifa

24 John OP, Srivastava S. The Big Five trait taxonomy: history, measurement, and theoretical perspectives. Handb Personal Theory Res 1999;2:102-38.

25 Newey WK. Efficient estimation of limited dependent variable models with endogenous explanatory variables. J Econom 1987;36:231-50.

26 Wooldridge JM. Econometric analysis of cross section and panel data. Second edition. Cambridge, Massachusetts: MIT Press, 2002.

27 Wagner-Menghin M, Pokieser P. Information technology and social sciences: how can health IT be used to support the health professional? Ann N Y Acad Sci 2016;1381:152-61.

28 Reis ZSN, Maia TA, Marcolino MS, et al. Is there evidence of cost benefits of electronic medical records, standards, or interoperability in hospital information systems? Overview of systematic reviews. JMIR Med Inform 2017;5:e26. 